\title{
Variabilidade espacial da resistência do solo à penetração avaliada ao longo de um cultivo de milho
}

Henrique José Guimarães Moreira Maluf

Universidade Federal de Viçosa, rick.maluf@yahoo.com.br

Diogo Santos Campos

Instituto Federal de Minas Gerais, campus Bambuí, diogo.campos@ifmg.edu.br

\section{Resumo}

O objetivo deste estudo é avaliar as variações espaciais da resistência à penetração em um Latossolo Vermelho Distroférrico típico em quatro profundidades e em três estágios fenológicos da cultura do milho. Aárea experimental foi cultivada sob um convencional preparo de solo, onde foi implantada a cultura do milho. Esta foi definida por uma malha quadrangular de $70 \mathrm{~m}$ x $70 \mathrm{~m}$, selecionada a partir de características visuais homogêneas, onde se estabeleceu 64 pontos georeferenciados distanciados de $10 \mathrm{em} 10 \mathrm{~m}$. As avaliações da resistência à penetração foram realizadas até $40 \mathrm{~cm}$ de profundidade em três estágios distintos da cultura (V6, VT e R6). As análises geoestatísticas e a geração dos mapas de variabilidade foram realizadas com o uso da versão gratuita do programa computacional GS+. Os resultados apresentam diferença entre as avaliações em cada perfil estudado, apresentando diferenciações nos modelos, na classificação da dependência espacial e no alcance desta dependência, o que dificulta a tomada de decisões pois estas mensurações sofrem influência de inúmeros fatores. O estudo permitiu uma maior visualização das influências nas medidas de resistência à penetração e alerta profissionais da área no uso destas para identificação de camadas compactadas.

Palavras-chave: Zea mays, Compactação, Geoestatística, Penetrômetro.

\section{Spatial variability of soil resistance to penetration measured over a corn crop}

\begin{abstract}
The objective of the study to evaluate the spatial variations of the resistance to penetration in an Oxisol typical, at four depth and three phenological stages of corn. The experimental area was cultivated in a conventional soil preparation, which was implemented in corn crop. This was defined by a rectangular grid of $70 \mathrm{~m} \times 70 \mathrm{~m}$, selected from homogeneous visual characteristics, where he settled 64 georeferenced points spaced from 10 to $10 \mathrm{~m}$. Evaluations of resistance to penetration were made up to $40 \mathrm{~cm}$ depth in three distinct stages of culture. The geostatistical analysis and generation of maps of variability were performed using the software GS+. The results show the differences in the models, the classification of spatial dependence and the extent of this dependence, complicating decision-making, only when using these measures to detect compacted layers, and these measurements are influenced by number of factors. The study allowed a better visualization of the influences on measures of penetration resistance, high lighting the soil moisture, and alert professionals use to identify these compacted layers.
\end{abstract}

Key-words: Zea mays, Compaction, Geostatistics, Penetrometer.

\section{Introdução}

A qualidade física assume importância na avaliação do grau de degradação do solo e na identificação de práticas de uso sustentáveis. Embora se admita que a verdadeira preocupação esteja com a qualidade física, esta tem afetado significativamente a qualidade química e biológica, já que são dependentes. Assim, a melhoria da qualidade física de determinado solo contribui indiretamente para a melhoria das suas condições químicas e biológicas (Dexter, 2004).

Uma das principais causas da degradação do solo é a compactação, resultado do processo de aumento da densidade e resistência à penetração. A compactação do solo ocorre de maneira muito frequente em ambientes que utilizam máquinas e 
implementos ou em áreas onde o pisoteio de animais é intenso, constituindo um dos mais sérios fatores de restrição ao desenvolvimento das plantas (Camargo; Aleoni, 1997).

A compactação do solo é um processo de densificação na qual há aumento da resistência do solo, redução da porosidade, da continuidade de poros, da permeabilidade e da disponibilidade de nutrientes e água. Esse processo reduz o crescimento e o desenvolvimento radicular, aumenta as perdas de nitrogênio por desnitrificação, o consumo de combustível para preparar solos compactados e a erosão do solo pela menor infiltração de água (Soane; Ouwerkerk, 1994).

Segundo Silva et al. (2010), para identificação da compactação, as propriedades físicas do solo mais usadas têm sido a densidade do solo, a resistência mecânica, porosidade total, o tamanho dos poros e sua continuidade, pressão crítica na qual os agregados sofrem cisalhamento e pressão de préconsolidação.

A resistência do solo à penetração é usualmente mensurada por meio de penetrômetros. De acordo com Sá e Santos Júnior (2005), a resistência mecânica que o solo oferece aos penetrômetros apresenta correlação com a resistência oferecida ao sistema radicular, sendo que os penetrômetros apenas simulam a resistência ao crescimento radicular. No entanto, a caracterização da compactação do solo com base em penetrometria e sua relação com o crescimento de raízes apresentam limitações, pois a resistência à penetração é extremamente variável em função do teor de água, da densidade do solo, do teor de argila e de matéria orgânica (Busscher et al., 1997; Imhoff et al., 2000).

O objetivo do estudo foi avaliar e analisar as variações espaciais da resistência à penetração em um Latosso Vermelho Distroférrico típico em quatro profundidades e em três estágios fenológicos da cultura do milho, e deste modo identificar sua eficiência como diagnóstico de camadas compactadas.

\section{Material e métodos}

O experimento foi conduzido na Fazenda Varginha, Km 05 da estrada Bambuí - Medeiros, pertencente ao Instituto Federal de Educação, Ciência e Tecnologia de Minas Gerais (IFMG), campus Bambuí. A área central do experimento estava localizada nas coordenadas geográficas $20^{\circ} 02^{\prime} 22^{\prime \prime}$ $\mathrm{S}$ e $46^{\circ} 00^{\prime} 27^{\prime \prime} \mathrm{O}$ com altitude média de 685 metros. O experimento foi implantado em um relevo caracterizado como suave ondulado. O material de origem do solo é do tipo calcário e o experimento se encontra em um Latosso Vermelho Distroférrico típico de textura argilosa (Embrapa, 2006).

A área experimental foi cultivada sob sistema convencional de preparo do solo onde foi implantada a cultura do milho (Zea mays Linnaeus) com a finalidade de produção de grãos, mantendo uma população de 64.705 plantas por hectare.

A área do experimento foi definida por uma malha quadrangular de $70 \mathrm{~m} \times 70 \mathrm{~m}$, totalizando $4.900 \mathrm{~m}^{2}$. Foram utilizadas, como critério de seleção da área, características visuais homogêneas, como topografia, cor do solo, vegetação, tratos culturais e irrigação. Os pontos da malha foram distanciados de $10 \mathrm{em} 10 \mathrm{~m}$, resultando em 64 pontos amostrais. Esses pontos, ilustrados pela Figura 1, foram identificados nas linhas pelas letras de "a" até "h" e colunas de 1 a 8.

Os pontos amostrais foram georeferenciados com o uso de um GPS Pathfinder Power da Trimble e pósprocessados com uso da estação de referência localizada na Prodabel em Belo Horizonte (MG). Esses dados foram usados na confecção do mapa da área com os respectivos pontos.

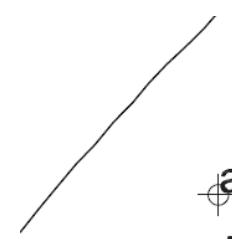

a.8<smiles>[Te][Te]</smiles><smiles></smiles><smiles>c1ccc2ccccc2c1</smiles>

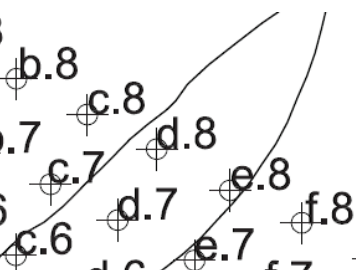<smiles>[AsH3]</smiles><smiles>[134I]</smiles>

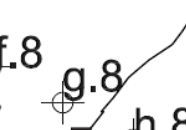

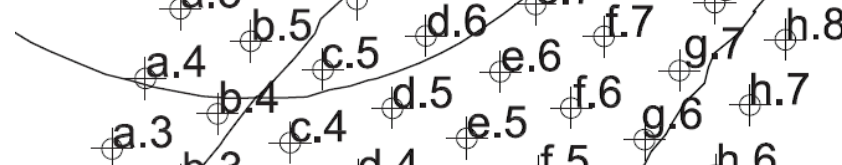

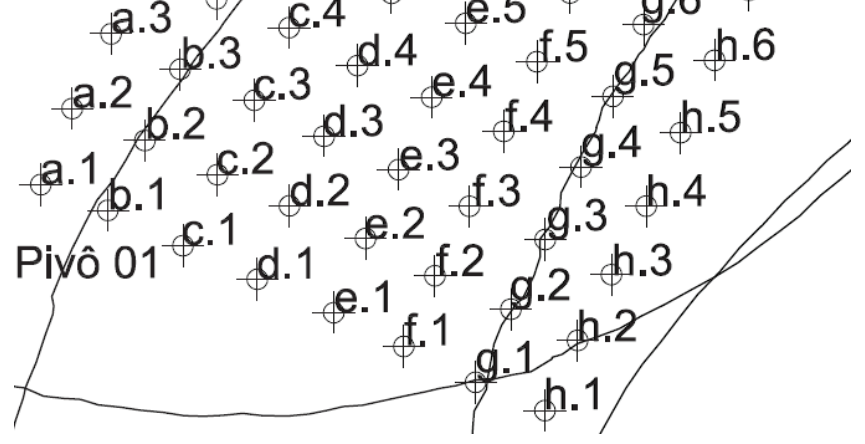

Figura 1. Malha fixa quadrangular georeferênciada.

Para a avaliação da resistência à penetração (RP), foram realizadas três repetições em cada um dos 64 pontos com o uso do penetrômetro PLG1020, penetroLOG - FALKER, analisando os dados até $40 \mathrm{~cm}$ de profundidade, destacados em o a 10, 10 a 20, 20 a 30 e 30 a $40 \mathrm{~cm}$, em três fases da cultura. A primeira no estágio fenológico V6, a segunda no estágio de VT (pendoamento) e a terceira na fase R6 (maturação fisiológica dos grãos). Durante o período das amostragens, a área não sofreu nenhum tipo de tráfego agrícola nem intervenção cultural que poderia influenciar nas características físicas do solo. A dependência espacial da RP foi avaliada utilizando a geoestatística. A semivariância foi estimada pela seguinte equação:

$$
\hat{\gamma}(\mathrm{h})=\frac{1}{2 \mathrm{~N}(\mathrm{~h})} \sum_{i=1}^{\mathrm{N}(\mathrm{h})}\left[\mathrm{Z}\left(\mathrm{x}_{\mathrm{i}}\right)-\mathrm{Z}\left(\mathrm{x}_{\mathrm{i}}+\mathrm{h}\right)\right]^{2}
$$


Em que $\gamma$ é a semivariância experimental, obtida pelos valores amostrados $Z(x i), Z(x i+h)$; h é a distância entre pontos amostrais e $\mathrm{N}(\mathrm{h})$ é o número total de pares de pontos possíveis, dentro da área de amostragem com distânciah (Vieira, 2000).

As análises geoestatísticas, a avaliação da isotropia e a geração dos mapas de variabilidade da RP foram realizadas com o uso da versão gratuita do programa computacional GS+ (Gamma design software, 2008) e os dados foram interpolados por meio da técnica da krigagem, a qual utiliza os parâmetros de semivariograma. A seleção dos modelos foi realizada com base no melhor coeficiente de determinação $\left(r^{2}\right)$, sendo testados os modelos esférico, exponencial, gaussiano e linear. Nos semivariogramas ajustados foram definidos os seguintes parâmetros: efeito pepita $\left(C_{0}\right)$; patamar $\left(C_{0}+C_{1}\right)$ e alcance da dependência espacial $\left(A_{0}\right)$. O quociente entre o efeito pepita e o patamar, $C_{0} /\left(C_{0}+C_{1}\right)$, permitiu a classificação da dependência espacial dos resultados.

Para avaliar o grau e realizar a análise da dependência espacial (ADE) dos resultados da RP, utilizou-se a classificação proposta por Cambardella (et al., 1994), em que os semivariogramas com dependência espacial forte possuem razão menor ou igual a $25 \%$, os semivariogramas com dependência espacial moderada possuem razão superior a $25 \%$ e inferior a $75 \%$ e os de dependência fraca possuem razão superior $75 \%$.

\section{Resultados e discussão}

Os resultados das análises geoestatísticas (Tabela 1) auxiliaram na compreensão e na melhor interpretação do comportamento destes no espaço. Os resultados permitiram observar uma grande diferença entre as avaliações, principalmente quando comparado o modelo de variograma, demonstrando tendências desiguais para uma mesma área e um mesmo perfil. De acordo com Santos (2006), os modelos são fundamentais na estimação de valores não amostrados e na compreensão da distribuição com os valores vizinhos. Deste modo, eles descrevem o fenômeno da dependência dos valores.

A ADE apresentou maior diferença na segunda avaliação, apresentando maior número de dependência moderada, demonstrando que seus valores nesta

\begin{tabular}{|c|c|c|c|c|c|c|c|}
\hline \multicolumn{8}{|c|}{ Primeira avaliação } \\
\hline $\begin{array}{l}\text { Prof. }{ }^{(1)} \\
\text { (cm) }\end{array}$ & $\mathrm{C}_{0}$ & $\mathrm{C}_{0}+\mathrm{C} 1$ & $\begin{array}{l}A_{0} \\
(m)\end{array}$ & $\begin{array}{c}C_{0} /\left(C_{0}+C 1\right) .100 \\
(\%)\end{array}$ & Modelo & $r^{2}$ & $\begin{array}{l}\text { Classificação } \\
\text { (ADE) }^{(2)}\end{array}$ \\
\hline $0-10$ & 100 & 79710 & 14,90 & 0,13 & Esférico & 0,68 & Forte \\
\hline $10-20$ & 6000 & 447800 & 17,80 & 1,34 & Esférico & 0,85 & Forte \\
\hline $20-30$ & 14000 & 525500 & 17,90 & 2,66 & Esférico & 0,79 & Forte \\
\hline $20-40$ & 1000 & 509200 & 15,00 & 0,19 & Esférico & 0,81 & Forte \\
\hline \multicolumn{8}{|c|}{ Segunda avaliação } \\
\hline $\begin{array}{l}\text { Prof. }{ }^{(1)} \\
(\mathrm{cm})\end{array}$ & $\mathrm{C}_{0}$ & $\mathrm{C}_{0}+\mathrm{C} 1$ & $\begin{array}{l}A_{0} \\
(m)\end{array}$ & $\begin{array}{c}C_{0} /\left(C_{0}+C 1\right) .100 \\
(\%)\end{array}$ & Modelo & $r^{2}$ & $\begin{array}{l}\text { Classificação } \\
\text { (ADE) }^{(2)}\end{array}$ \\
\hline $0-10$ & 15740 & 45060 & 35,40 & 34,93 & Gaussiano & 0,98 & Moderada \\
\hline $10-20$ & 125000 & 461000 & 57,10 & 27,11 & Gaussiano & 0,96 & Moderada \\
\hline $20-30$ & 200 & 153000 & 10,00 & 0,13 & Gaussiano & 0,96 & Forte \\
\hline $20-40$ & 140300 & 427800 & 97,50 & 32,80 & Esférico & 0,96 & Moderada \\
\hline \multicolumn{8}{|c|}{ Terceira avaliação } \\
\hline $\begin{array}{l}\text { Prof. }{ }^{(1)} \\
\text { (cm) }\end{array}$ & $\mathrm{C}_{0}$ & $\mathrm{C}_{0}+\mathrm{C} 1$ & $\begin{array}{l}A_{0} \\
(m)\end{array}$ & $\begin{array}{c}C_{0} /\left(C_{0}+C 1\right) .100 \\
(\%)\end{array}$ & Modelo & $r^{2}$ & $\begin{array}{c}\text { Classificação } \\
\text { (ADE) }^{(2)}\end{array}$ \\
\hline $0-10$ & 2340 & 32150 & 12,60 & 7,28 & Esférico & 0,50 & Forte \\
\hline $10-20$ & 2600 & 61660 & 4,70 & 4,21 & Exponencial & 0,30 & Forte \\
\hline $20-30$ & 8000 & 88690 & 7,80 & 9,02 & Exponencial & 0,66 & Forte \\
\hline $20-40$ & 37400 & 87610 & 8,30 & 42,69 & Exponencial & 0,41 & Moderada \\
\hline
\end{tabular}

Tabela 1. Resultados dos semivariogramas, como valores do efeito pepita $\left(C_{0}\right)$, patamar $\left(C_{o}+C_{1}\right)$, alcance $\left(A_{o}\right)$, relação efeito pepita/patamar, coeficiente de determinação $\left(r_{2}\right)$ e a classificação do grau de dependência espacial dos modelos ajustados, para cada avaliação e para as profundidades estudadas. Legenda: (1) Profundidade de avaliação; (2) Análise da dependência espacial, proposto por Cambardella et al. (1994). 
avaliação não possuem grande dependência entre os valores vizinhos.

Outro ponto que difere dos resultados da primeira avaliação é o Ao, do qual em outras avaliações foi possível encontrar valores maiores que a distância dos pontos amostrais, demonstrando que estes resultados apresentam um comportamento aleatório, sem necessidade do uso da teoria geoestatística, e sim da estatística clássica. Contudo, os resultados das avaliações possuem uma tendência e um comportamento diferente para uma mesma área, apresentando diferenciações altas para cada perfil estudado.

Os mapas de variabilidade espacial, apresentados nas Figuras 2 a 5, facilitam a visualização dos resultados apresentados na tabela supracitada e permite uma melhor comparação das avaliações em cada perfil.

\section{Primeira avaliação}
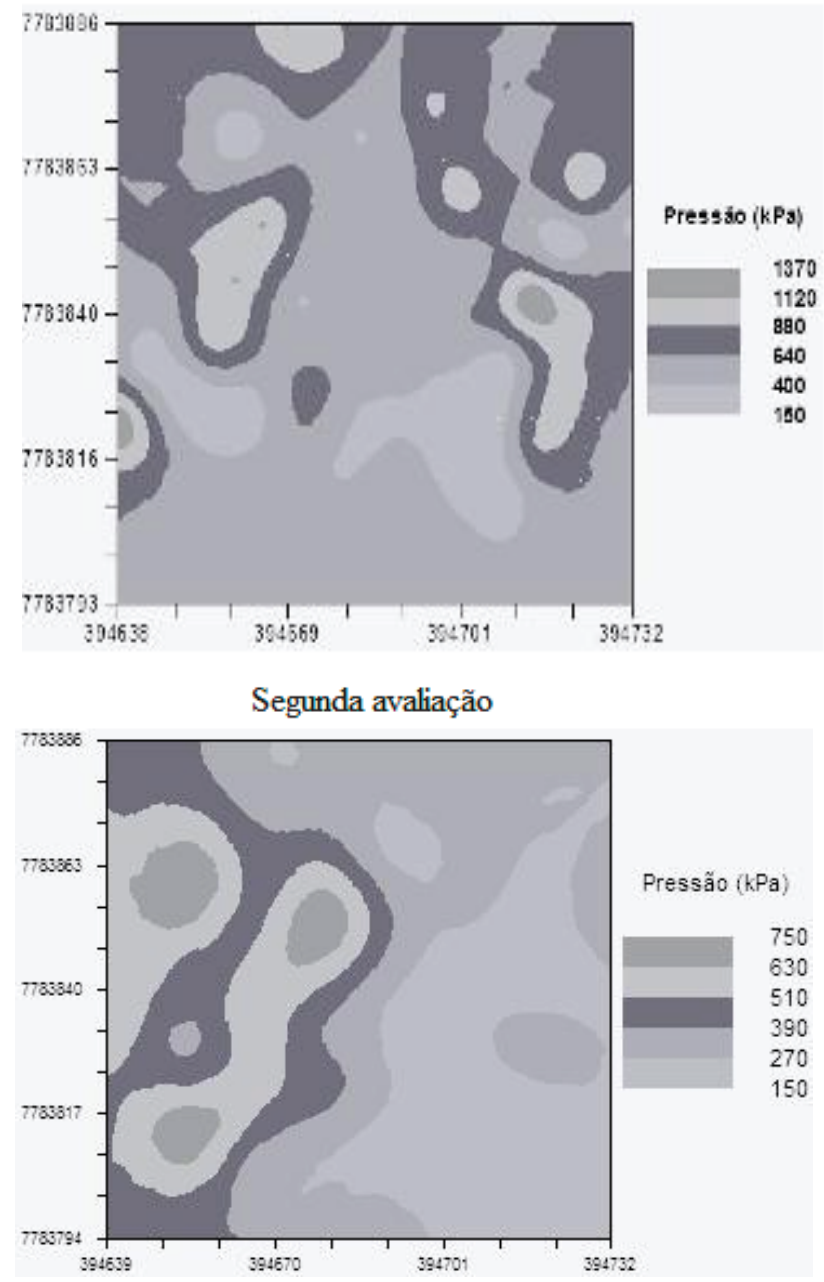

Pressão $(\mathrm{kPa})$

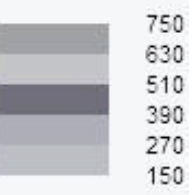

Terceira avaliação

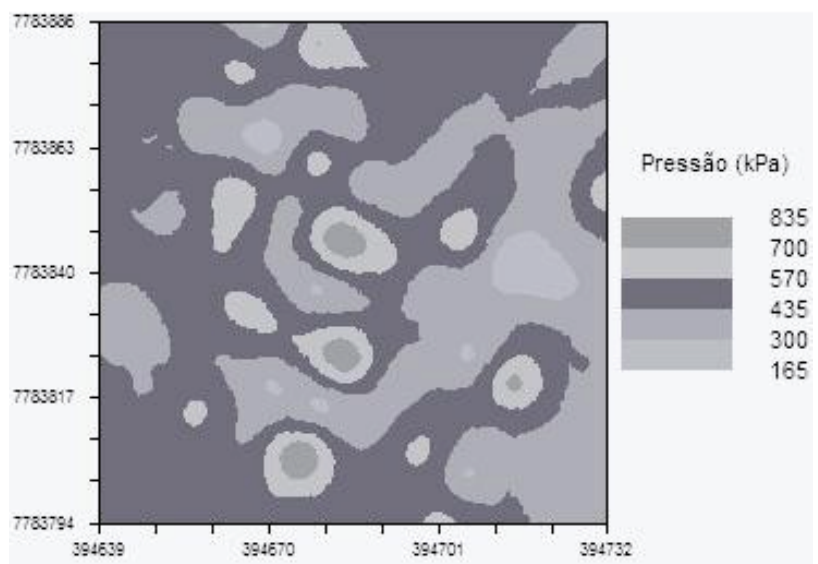

Figura 2 - Mapas da variação espacial da RP nas profundidades de o a $10 \mathrm{~cm}$, nas três avaliações realizadas ao longo do ciclo da cultura do milho.
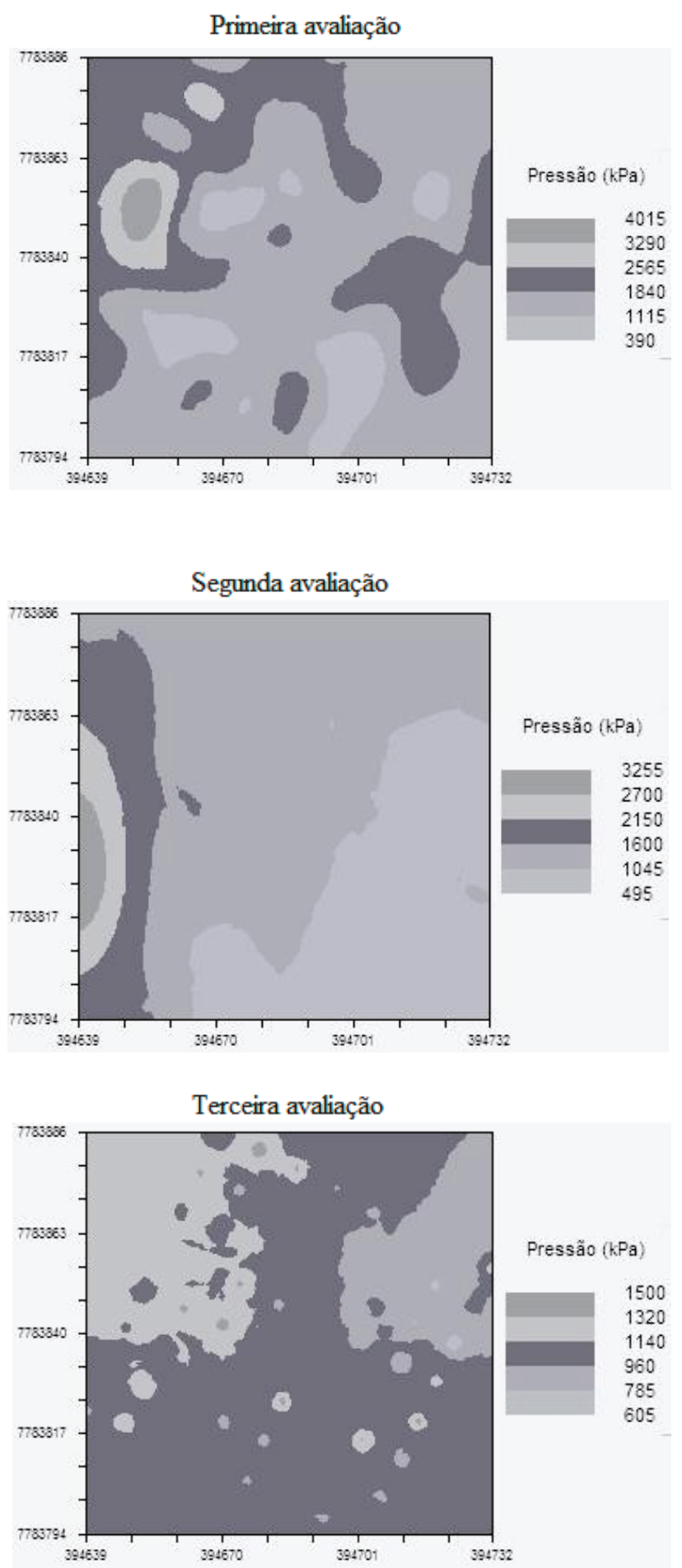

Figura 3 - Mapas da variação espacial da RP nas profundidades de 10 a $20 \mathrm{~cm}$, nas três avaliações realizadas ao longo do ciclo da cultura do milho. 


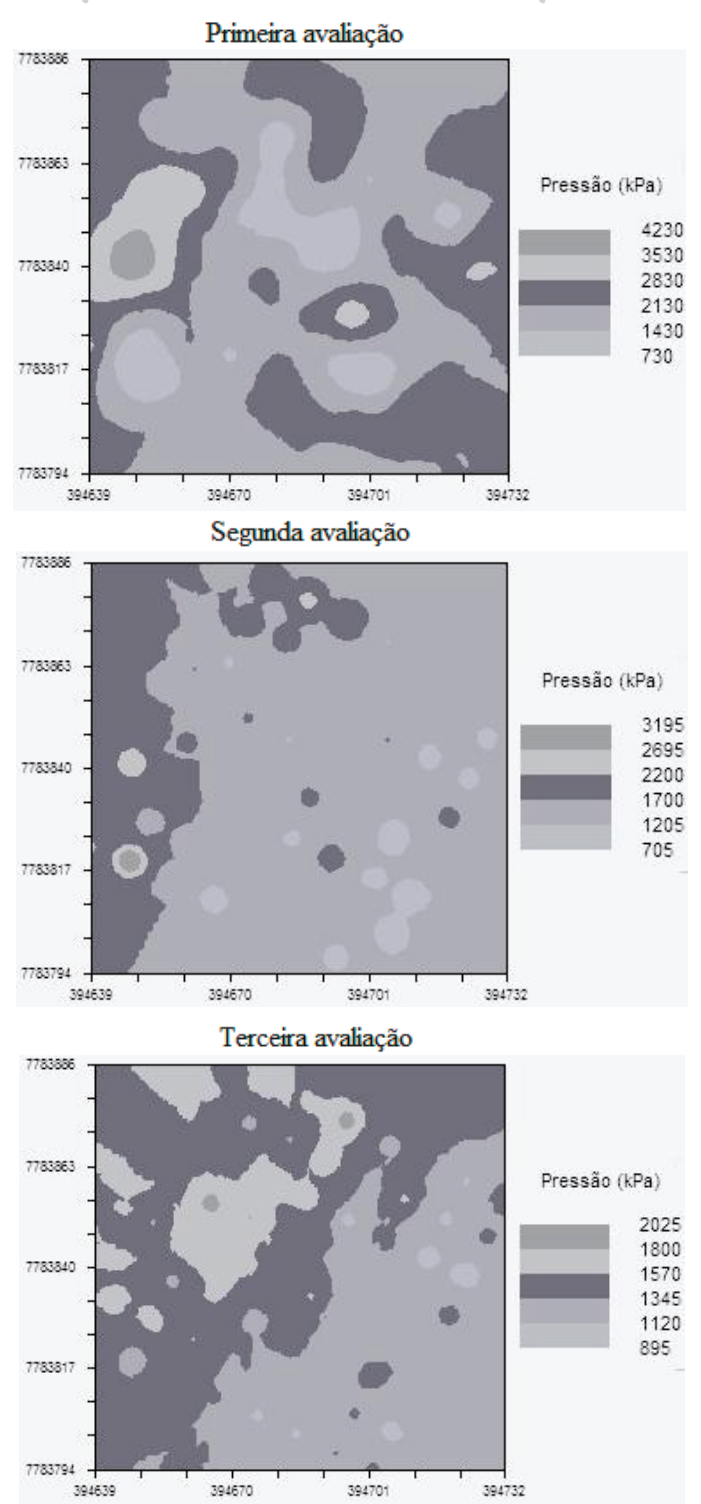

Figura 4 - Mapas da variação espacial da RP nas profundidades de 20 a $30 \mathrm{~cm}$, nas três avaliações realizadas ao longo do ciclo da cultura do milho.

Sabendo que as camadas avaliadas de o a 10 e 10 a 20 $\mathrm{cm}$ possuem maior teor de matéria orgânica que as camadas subsequentes, observa-se que independente dessas, as camadas de 20 a 30 e 30 a $40 \mathrm{~cm}$ continuaram a apresentar variações entre as avaliações.

Conforme Grant e Lanfond (1993), os valores limitantes de RP para o crescimento radicular de grande parte das culturas variam de 1500 a $3000 \mathrm{kPa}$. Para Arshad (et al., 1996), estes valores variam de 2000 a $4000 \mathrm{kPa}$. De acordo com esses valores, os mapas demonstram conflito entre as avaliações, tanto nos níveis da pressão de resistência em que alcançam, quanto na localização em que se apresentam, dificultando qualquer possibilidade de intervenção para a melhoria da situação apresentada.

A RP é uma medida relativamente fácil de ser mensurada, mas deve se tomar precauções quando utilizada como indicadora de níveis de compactação, sendo que nem sempre a RP tem correlação com a densidade do solo. Segundo Maluf (et al., 2011), a RP e a densidade do solo não apresentaram relação e ambas não demonstraram similaridade na variação espacial, nas

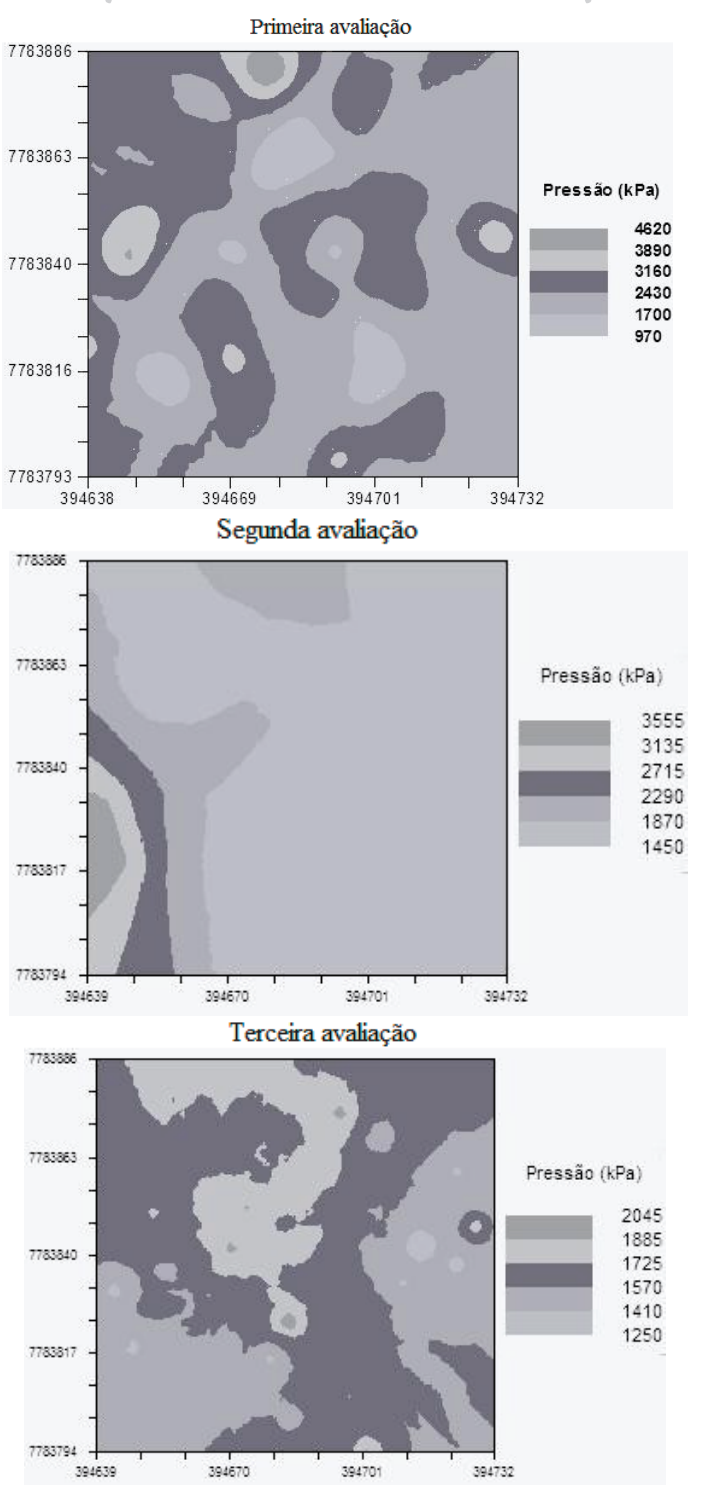

Figura 5 - Mapas da variação espacial da RP nas profundidades de 30 a $40 \mathrm{~cm}$, nas três avaliações realizadas ao longo do ciclo da cultura do milho.

condições estudadas pelos autores. Este fato pode ser explicado por Silva (et al., 2004), que afirmaram que a RP é bastante variável, sendo muito influenciada por condições do manejo do solo, intensidade de tráfego de máquinas, além de depender da umidade do solo. A densidade do solo é uma medida mais direta e menos influenciada pela umidade.

Ribon e Tavares Filho (2008) observaram variações de alta a muito alta nas determinações da RP, caracterizando alta variabilidade espacial, sendo a Ds obtendo variações muito abaixo do que o encontrado na RP, desse modo não encontrando relações entre os dois atributos.

Dois dos principais fatores que influenciam as medidas de RP são a textura e a umidade, principalmente a umidade, por ser fator de grande variação no decorrer de um pequeno período e porque o teor de água no solo é grande fator limitante para o crescimento radicular.

De acordo com Perumpral (1987), e aceito até os dias atuais, os penetrômetros vêm sendo empregados em grande escala no meio agrícola, para diversas aplicações, por serem de utilização fácil, rápida e barata, com fácil 
interpretação dos resultados, principalmente para a determinação da resistência do solo à penetração de raízes e detecção de camadas de solo compactadas. No entanto, esses equipamentos são acionados manualmente, podendo causar imprecisões de leitura, como alertaram Camargo e Alleoni (1997).

Da mesma forma que o equipamento deve ser manuseado com alguns cuidados, não se pode afirmar, com exatidão, que somente o uso da penetrometria é capaz de detectar camadas compactadas do solo, embora alguns autores tenham se esforçado para propor modelos eficientes que relacionam as medidas de RP com os fatores que os influenciam.

\section{Conclusão}

O estudo da variabilidade espacial com uso da estatística espacial permitiu identificar e visualizar grandes variações ao longo do tempo na determinação da resistência à penetração. Assim, os resultados apresentados neste trabalho podem servir de alerta aos profissionais que utilizam penetrômetros para identificação de camadas compactadas em áreas agrícolas.

\section{Referências bibliográficas}

ARSHAD, M.A.; LOWERY, B. \& GROSSMAN, B. Physical tests for monitoring soil quality. In: DORAN, J.W. \& JONES, A.J., eds. Methods for assessing soil quality. Madison, Soil Science Society of America. 1996. p. 123-141 (SSSA Special publication 49).

BUSSCHER, W. J.; BAUER, P. J.; CAMP, C. R.; SOJKA, R. E. Correction of cone index for soil water content differences in a coastal plain soil. Soil and Tillage Research, Amsterdam, v. 43, p. 205-217, 1997.

CAMARGO, O. A.; ALLEONI, L. R. F.. Compactação do solo e o desenvolvimento das plantas. Piracicaba-SP, Degaspar, 1997.132p.

CAMBARDELLA, C. A.; MOORMAN, T. B.; NOVAK, J. M.; PARKIN, T. B.; KARLEN, D. L.;. TURCO, R. F.; KONOPKA, A. E. Field-scale variability of soil properties in Central lowa Soils. Soil Science Society of American Journal, Madison, v.58, n.5, p.1501-11, 1994.

DEXTER, A. R. Soil physical quality. Part I. Theory, effects of soil texture, density, and organic matter, and effects on root growth. Geoderma, v.120, p.201-214, 2004.

EMBRAPA, Centro Nacional de Pesquisa de Solos. Sistema brasileiro de classificação de solos. Brasília, DF: Embrapa Produção de Informação; Rio de Janeiro, Embrapa Solos, 412 p., 2006.
GAMMA DESIGN SOFTWARE. Geoestatistics for the environmental sciences (version 9 for windows). Michigan, 2008.

GRANT, C.A. \& LAFOND, G.P. The effects of tillage systems and crop sequences on soil bulk density and penetration resistance on a clay soil in southern Saskatchewan. Canadian Journal of Soil Science., 73:223-232, 1993.

IMHOFF, S.; SILVA, A. P.; TORMENA, C. A. Aplicações da curva de resistência no controle da qualidade física de um solo sob pastagem. Pesquisa Agropecuária Brasileira, Brasília, DF, v. 35, n. 7, p.1493-1500, 2000.

MALUF, H. J. G. M.; CAMPOS, D. S.; COSTA, S. G.; LUIZ, A. A.; TORMEN, G. P. Variabilidade espacial da resistência do solo à penetração e da densidade de um latossolo vermelho distroférrico típico. In: XXXIII CONGRESSO BRASILEIRO DE CIÊNCIA DO SOLO, 2011, Uberlândia. Anais..., 2011.

PERUMPRAL, J.V. Cone penetrometer applications - a review. Transaction of the ASAE, St. Joseph, v.30, n.4, p.939-944, 1987.

RIBON, A. R.; TAVARES FILHO, J. Estimativa da resistência mecânica à penetração de um Latossolo Vermelho sob cultura perene no norte do estado do Paraná. Revista Brasileira de Ciência do Solo, 32:1817-1815, 2008.

SÁ, M.A.C.; SANTOS JUNIOR, J.D.G. Compactação do solo: Consequências para o crescimento vegetal. Planaltina, Embrapa Cerrados, 2005. 26p. (Embrapa Cerrado/ Documento, 136)

SANTOS, N. T. Estatística espacial aplicada. Viçosa, MG: UFV. 2006.327p. (Apostila DPI-UFV).

SILVA, A. P.; TORMENA, C. A.; DIAS JÚNIOR, M. S.; IMHOFF, S.; KLEIN, V. A. Indicadores da qualidade física do solo. In: LIER, Q. J. V. Física do solo. Viçosa, MG: Sociedade Brasileira de Ciência do Solo, 2010. Cap. VII, p. 241-281.

SILVA, V. R.; REICHERT, J. M.; REINERT, D. J. Variabilidade espacial da resistência do solo à penetração em plantio direto. Ci. Rural, 34:399-406, 2004.

SOANE, B.D., OUWERKERK, C. van. Soil compaction problems in world agriculture. In: SOANE, B.D., OUWERKERK, C. van, (eds). Soil compaction in crop production. Netherlands: Elsevier, 1994. p.1-21.

VIEIRA, S. R. Geoestatística em estudos de variabilidade espacial do solo. In: UFV - Universidade Federal de Viçosa. Tópicos em Ciências do Solo. Viçosa: SBCS, 2000. 